\title{
Strategies in Inculcating Environmental Responsible Behaviour in Abia State, Nigeria Using Community - Based Social Marketing
}

\author{
Patrick A. Ogwo \\ Department of Environmental Management \&Toxicology Michael Okpara University of Agriculture, Umudike, \\ Nigeria
}

\begin{abstract}
In order to check the menace of soil erosion and save the campus environment, a number of measures were put in place by the Abia State University Administration including planting of lawn grasses, construction of walkways and erection of barricades. In spite of these measures, majority of our people still engage in environmentally irresponsible behaviour. The objective of this paper was to device a strategy in inculcating environmental responsible behaviour among the University Community through the use of community based social marketing. Community - Based Social Marketing is a non-coercive approach to change in behaviour and has been shown to have promise in facilitating community adoption of conservation practices than the conventional information and economic self interest approach.

The study used self-administered questionnaires to examine respondents' awareness of and engagement in environment behaviour. The survey was conducted in Abia State University in the 2007/2008 academic year. Results showed that:

1. Respondents adopted the use of walkway in order to save the environment and the major barrier to the use of walk way was forgetting followed by apathy.

2. The major benefit of using source separation resource bins was to reduce wastes that were disposed and the major barrier to use of source separate bins was forgetting, followed by inconvenience.

3. Respondents appeared to respond to picking of litters on campus when the National Universities Commission Accreditation Teams visited the campus. NUC scores for environmental cleanliness and safety in evaluating courses/programmes for full accreditation. Further research is required to identify barriers and benefits associated with environmental responsible behaviours in other campuses of the Nigerian Universities in order to ascertain whether engagement in one practice prompts engagement in similar behaviours.
\end{abstract}

Keywords: Environmental behaviour, community based social marketing, source separation of campus waste.

\section{Introduction}

Abia State University is located on an ecologically sensitive site. The soils and terrain are such that the university is prone to erosion. Erosion has threatened to cut off the major link between the students' hostels and faculty buildings. Most of the facilities are at risk of collapsing into the gullies. Among the facilities being threatened include the University Mega Library, MJC Echeruo Faculty of Humanities and Social Sciences Building, Faculty of Business Administration. The University commits huge sums of money in checking the menace of soil erosion on campus. These measures include planting of lawn grasses, construction of walk ways and erection of barricades in major areas on campus. The objective is to protect and beautify the fragile University environment.

Despite these efforts in creating walk ways, and the instruction by the Vice Chancellor for people to use the walk ways, majority of our people still walk across the lawns, throw and litter refuse around the university campus and in the classroom. Ogwo et.al(2013) noted that a number of undesirable environmental impacts including blockage of water ways and rivers, choking of animals and the mosaic litters of pure water sachets in the landscape require urgent attention .Externalities are the primary cause of the plastic problem: external costs from end-of -life environmental impacts and resource depletion are not factored in the products costs ,resulting in plastics being so cheap that they are given away ' for free' which serve the profligate use -and throw pattern of consumption and production. Institutional ,policy failures and inadequacy of environmental bylaws to deter littering and illegal dumping also contribute to the problem. The objective is to device a strategy in inculcating environmental responsibility behaviour among the University Community.

This paper reports a research project that uses community based social marketing principles to inculcate environmental responsible behaviour on students and staff of Abia State University. The project has targeted a range of environmental action e.g. use of walk ways instead of walking on the lawns, use of source 
separation. Resource Bins instead of indiscriminate dumping and littering of refuse, leaf litter collection and composting instead of burning etc. Community Based Social Marketing (CBSM) has been shown to have promise in facilitating community adoption of conservation practices (Ebreo and Vining, 1999) CBSM is a noncoercive approach to change in behaviour.

It has been observed that our campus would be more sustainable if staff, students and visitors alike use the walkways instead of walking across the lawns, use the source separation resource bins instead of indiscriminate dumping the littering of the classroom and harvest leaf litters for composting instead of setting them ablaze. How can we inculcate these responsible behaviours to the University community?

Most programs to foster sustainable behaviour rely upon large-scale information campaigns. Information-based campaigns usually assume that changes in behaviour are brought about by increasing public knowledge about an issue; such as source separation of waste, and by fostering attitudes that are supportive of a desired activity such as compositing. Programmes based on this perspective attempt to alter behaviour by providing information through media advertising, bills boards and frequently the distribution of brochures, flyers and newsletters i.e. by enhancing knowledge or altering attitudes behaviour will change. Numerous studies have shown that education alone often has little or no effect upon sustainable behaviour (MckenzieMohr and Smith, 1999).

This school of thought assumes that individuals systematically evaluate choices and then act in accordance with their economic self-interest and suggests that in order to affect individual decisions, a community or organization needs only provide information to the public that something is in their financial best interest and consequently the public will behave accordingly. According to Stern and Oskamp (1997), economic self-interest unlike the information approach that focuses on altering knowledge and attitude, concentrates on pointing out the financial advantages of a sustainable activity, such as offering students money to pick pure water sachets on campus. Environmental education is necessary for a change in the behaviour of students and staff toward recycling, picking up litter and source separation of wastes.

Fishbein and Ajzen (1975) observed that attempts to influence individual's environmental behaviour, attitudes and knowledge have been predominantly framed within theories of persuasive communication such as the theory of Reasoned Action and the theory of planned behaviour. These theories state that the content of interpretive programmes are most likely to lead to changes in behavioural intentions if they are built upon the target audience's beliefs about a particular issue or behaviour. They are of the opinion that to develop effective and persuasive conservation messages, individuals should first identify salient or important beliefs about specific conservation issues or practices and then design programme that address these beliefs thereby fostering positive attitudes and intention towards adopting the targeted practices. It has become apparent however that positive attitudes towards environmental behaviour and stated intentions to engage in such practices do not necessarily lead to subsequent action.

\section{Materials and Methods}

A self - administered questionnaire that examined respondent's awareness of and engagement in, the practices listed already was designed and pilot - tested with ten respondents. Questions were open - tested and were designed to probe firstly, why students and staff do or do not currently engage in these environmental responsible practices and secondly, to ascertain what benefits they associate with the selected practices.

The survey was conducted at Abia State University, Uturu during the second semester of the 2007/2008 academic year.

\section{Respondents}

The sample comprised 72 females, 21 male students and 7 students who did not indicate their gender.

The majority of respondents were in their twenties (33\%) Questionnaire responses were analyzed using qualitative content analysis and the data reduced into categories according to methods suggested by Jennings (2001).

\section{Use of Walkways}

Respondents were asked to indicate on a five point scale ranging from never to always how often they used the walkways instead of walking on the grass lawns. The majority claimed to use the walkway sometimes $(39 \%)$ or often $31 \%$, though a small proportion $11 \%$ had never used the walkways. The mean score on this item was 3.17. The benefits associated with using the walkway commonly cited to respondents are listed: in Table I.

\section{Table I}

The barriers preventing the use of walkways by students are also presented in table I. Respondents felt that the most common problem is forgetfulness ( $60 \%$ of the sample).Apathy and a reluctant to go back and use the walkway were mentioned by $32 \%$ and $17 \%$ of respondents respectively. 
These responses suggest that increasing behaviour in the use of walkways requires persuasion and messages that explain the environmental benefits of maintain the walkways e.g, reduced soil erosion, aesthetics, etc. The environmental dangers posed by not using the walkways should also be highlighted. As the main barrier preventing people from using the walkway was forgetfulness, reminder strategies e.g. stickers and prompts that can be placed at the point of entry of the walkway could be developed.

\section{Use of the Source Separation Bins}

Respondents were asked to indicate how often they have used the Source Separation bins ranging from never to always. The majority claimed they had never used Bins. Sometimes (32\%) or often 31\%, though a small proportion (11\%) always used the bins.

The benefits associated with the use of SSB are listed - Table 2 Respondents were asked to suggest what might prevent people from using the SSB. The second column of Table 2 shows that over half of the group $(53 \%)$ felt that forgetting was an issue; poor understanding of what forgetting was an issue; poor understanding of what the SSB is all about $(16 \%)$.

\section{Picking up Litter on Campus}

Most respondents stated that they never pick up litter on campus (57\%).

To identify factors that could encourage people to pick up litter respondents were asked to explain the circumstances under which they could engage in the practice. Responses suggest that external factors such as visitors during NUC or professional accreditation play a strong role in determining the likelihood of litter being removed. As Table 3 illustrates, people are most likely to remove litter when the campus is facing accreditation by either National Universities Commission $(39 \%)$ or when there were events on campus like matriculation $(27 \%)$ and convocation $(20 \%)$.

Lack of knowledge on what picking litter is all about appears to be important barrier to picking up litter on campus. Other factors respondents felt were most likely to prevent picking up litter were lack of concern $(30 \%)$ as respondents indicated that it was not their fault that the campus is littered in the first place. The aesthetic benefits of picking up rubbish on campus should be highlighted.

A series of chi-squares for independent samples were conducted. There were no significant relationship between age and any of the practices measured. (Use of walkways $\mathrm{X}^{2}=4.060, \mathrm{P}=.398$; use of source Separation resource bins $\mathrm{X}^{2}=6.277, \mathrm{P}=.179$; picking of litter on campus $\mathrm{X}^{2}=4.448, \mathrm{P}=.349$. That is patterns of engagement in these practices are similar across age groups. Similarly there was no significant relationship between year of study in the University and programme of study and the practices measured (use of walkways $\mathrm{X}^{2}=0.739, \mathrm{P}=0.691$, use of source separation resource bins $\mathrm{X}^{2}=0.696 ; \mathrm{P}=706$; picking of litter on campus $\mathrm{X}^{2}=0.0880 ; \mathrm{P}=.644$. This finding suggests that engagement in those practices is similar regardless of year of programme of study. This findings support a range CBSM studies which indicates that demographic variables have limited value in predicting the behaviour such as recycling (Granzin and Olsen, 1991).

Chi - square for independent samples were also used to explore relationship between the practices measured. There were significant relationship between respondents engagement in use of source Separation Resource Bins and picking up of litter on Campus $\left(\mathrm{X}^{2}=11.865, \mathrm{P}=.008\right)$ Use of source Separation resource bins and use of walkways $\left(\mathrm{X}^{2}=6.124, \mathrm{P}=0.0047\right)$; and picking up litters and use of walkways $\left(\mathrm{X}^{2}=18.640, \mathrm{P}\right.$ $0.017)$.

\section{Conclusion and Implication}

1. Respondents adopt the use of walkway in order to save the environment and the major barrier to the use of walk way is forgetting followed by apathy.

2. The major benefit of using source separation resource bins is to reduce wastes that are disposed and the major barrier to use of source separate bins is forgetting, followed by inconvenience.

3. Respondents appear to respond to picking of litters on campus when the National Universities Commission Accreditation Teams visit the campus. NUC scores for environmental cleanliness and safety in evaluating courses/programmes for full accreditation. Further research is required to identify barriers and benefits associated with environmental responsible behaviours in other campuses of the Nigerian Universities in order to ascertain whether engagement in one practice prompts engagement in similar behaviours. 
Table 1: Most commonly cited benefits and barriers associated with the use of walkways in Abia State University

\begin{tabular}{|l|c|l|c|}
\hline Benefits of Using the Walkways & Freq. & Barriers to Using the Walkways & Freq. \\
\hline Saves environment & 52 & Forgetting & 60 \\
\hline Reduce environmental problem & 40 & Apathy & 32 \\
\hline Have less impact on natural resources & 18 & Inconvenience & 17 \\
\hline Improves the campus aesthetics & 14 & Lack of knowledge & 14 \\
\hline Controls erosion & 12 & & \\
\hline Reduces pollution & 8 & & \\
\hline
\end{tabular}

Table 2 Most commonly cited Benefits and Barriers associated with the use of Source Separation Resource Bins.

\begin{tabular}{|l|l|l|l|}
\hline Benefits of Using Source Separation Bins & Freq. & Barriers to Use of SSB & Freq. \\
\hline Reduces waste/landfill I & 35 & Forgetting to Use Bins & 53 \\
\hline Saves environment & 32 & Inconvenience & 18 \\
\hline Reduces littering on Campus & 13 & Apathy & 16 \\
\hline Enhances Resource re-use & 12 & Bins are not empted often enough & 8 \\
\hline Reduces Pollution & 8 & & 5 \\
\hline
\end{tabular}

Table 3: Circumstances under which respondents would or would not pick litter on Campus.

\begin{tabular}{|l|c|l|c|}
\hline Facilities to picking up litter & Freq. & Barriers to picking up litter & Freq. \\
\hline During NUC Accreditation & 39 & Lack of knowledge on what pick up litter is all about & 42 \\
\hline During Matriculation & 27 & Litter is not my fault & 30 \\
\hline During Convocation & 20 & No compulsory facilities & 22 \\
\hline Whenever I see litter & 8 & No bins nearby & \\
\hline On clean-up days & 6 & & \\
\hline
\end{tabular}

\section{References}

[1]. Ebreo, A. and Vining, J. (2001). How similar are recycling and waste reduction? Future Orientation and reasons for reducing waste as predictors of self-reported behaviour. Environment and Behaviour, 33(3) $424-448$

[2]. Fishbein, M. and Ajzen, I. (1975). Belief, attitudes, intentions and Behaviour: An Introduction to theory and research. Reading, MA, Addison - Wesley.

[3]. Jennings, G. Tourism research Milton, Queensland, John Wiley and Sons.

[4]. Marcell, K., Agyeman, J., and Rapaport, A. (2004). Cooling the Campus: Experiences for a pilot study to reduce electricity use at Tufts University, USA, using Social marketing methods. International Journal of Sustainability in Higher Education, 5 (2), 169 189

[5]. Mckenzie - Mohr, D. and Smith, W. (1999). Fostering Sustainable behaviour: An Introduction to Community-based Social Marketing. Babriola Island, B.C., Canada, New Society Publishers.

[6]. Ogwo, P.A., Obasi, L.O., Okoroigwe, D.S., and Dibia, N.O.(2013) From Plastic Bag Wastes to Wealth: A case Study of Abia State University, Nigeria Journal of Environmental Management and Safety

[7]. Stern, P.C. and Oskamp, S. (1987). Managing Scara Environmental Resources. In D. Stokols and I. Altman (eds). Handbook of Environmental psychology, Vol. 2 pp. 1043 -1088. John Wiley and Sons, New York. 